\title{
COST-EFFECTIVE AND INNOVATIVE TEST JIG FOR FISHING-BAIT RELEASE MECHANISMS ATTACHED TO DRONES
}

Pierre Eduard Hertzog

Department of Electrical, Electronics and Computer Engineering

Central University of Technology, Bloemfontein, (South Africa).

E-mail: phertzog@cut.ac.za ORCID: http://orcid.org/0000-0002-3396-6050

Arthur James Swart

Department of Electrical, Electronics and Computer Engineering

Central University of Technology, Bloemfontein, (South Africa).

E-mail: aswart@cut.ac.za ORCID: http://orcid.org/0000-0001-5906-2896

\section{Gitación sugerida Suggested citation}

Hertzog, P. E., y Swart, J. (2020). Cost-effective and innovative test jig for fishing-bait release mechanisms attached to drones. 3 C Tecnología. Glosas de innovación aplicadas a la pyme. Edición Especial, Abril 2020, 119-135. http://doi.org/10.17993/3ctecno.2020.specialissue5.119-135 


\section{ABSTRACT}

Fishing-bait release mechanisms are used in conjunction with drones to drop bait at a specific fishing location. It is really a revolutionary technology to many fishermen. However, many of these release mechanisms have no real technical data associated with them. Therefore, the purpose of this paper is to present a cost-effective and innovative test jig that may be used to determine the reliability and consistency of operation of various fishing-bait release mechanisms. The main components of the system are a HX711 instrumentation amplifier, a load cell and an Arduino Mega microcontroller. The accuracy of the system was determined to be $99,879 \%$. Reliability values for a Gannet Sport mechanism with a $0.55 \mathrm{~mm}$ Kingfisher line ranged from $599 \mathrm{~g}$ to $642 \mathrm{~g}$, giving a maximum deviation of $43 \mathrm{~g}$. The results provide evidence that the system is both reliable and valid. It is recommended to use it to clarify technical data regarding the weights at which different fishing-bait release mechanisms operate.

\section{KEYWORDS}

Arduino, Load-cell, Electronic measurements. 


\section{INTRODUCTION}

"A few years ago, the city council of Monza, Italy, barred pet owners from keeping goldfish in curved bowls... saying that it is cruel to keep a fish in a bowl with curved sides because gazing out, the fish would have a distorted view of reality. But how do we know we have the true, undistorted picture of reality?" ("Brainy Quote", 2019). These words by the late world-renowned physicist, Stephen Hawking, illustrates that our perception of reality may be distorted, just as the viewpoint of a fish may be distorted in a curved glass bowl. To correct this distortion would require that we obtain accurate knowledge based on facts.

However, we would first need to de-construct our erroneous knowledge and then reconstruct it with the accurate knowledge that we have received. De-constructing knowledge must be preceded by an acknowledgement that our knowledge, or perceptions, may be erroneous, or even biased. This is true even of simply things in life, such as fishing.

Fishing is as old as the hills, yet as new as today when it comes to new and innovative equipment and technologies. For example, drones have been used in fishing to identify good fish spots and for bait release purposes. The Internet of Things and fishing drones using an integrated remote camera have been used to target specific fishing spots to enable easier catching of fish (Maksimovic, 2018). Fishing for large fish beyond the breakers by first looking for them and then dropping the bait and a hook in front of them is quite popular in South Africa and can be achieved by using a fishing line dropping drone (SUAS News, 2019). This may also be termed a fishing-bait release mechanism that is attached to the bottom of a drone, which is really a revolutionary technology to many fishermen.

However, with so many different models available for this type of technology, the question may arise "Which release mechanism is more reliable and consistent in operation? Some fishermen may prefer the old tradition of casting the fishing line, while others may have strong opinions about a preferred modernized technology that makes use of a fishing-bait release mechanism. De-constructing erroneous perceptions of which model is best, and then re-constructing knowledge of which model is reliable and consistent would require the use of one or other scientifically accepted test. 
The purpose of this paper is to present a cost-effective and innovative test jig that may be used to determine the reliability and consistency of operation of various fishing-bait release mechanisms. The paper starts with a brief history of drone technology and presents some of its many applications. Previous research in the field of release mechanisms are also presented. The design of the jig is then given, followed by the methodology employed to obtain the scientific empirical results. Conclusions end the paper.

\section{LITERATURE}

Some believe that the first type of drone was used in July 15, 1849 when the Habsburg Austrian Empire launched 200 pilotless balloons armed with bombs against the revolutionminded citizens of Venice (Ferrao, 2016). However, others view this as an erroneous belief, especially when considering the official definition given by The Oxford Dictionary. It defines a drone as "a remote-controlled pilotless aircraft or missile" ("Oxford Dictionary", n.d.). The aspect of remote-control and flight must be factored into the discussion. The Federal Aviation Administration (FAA) of the USA further defines a drone as a small unmanned aircraft system weighing under $55 \mathrm{lb}$ (or 24,9 kg) (Federal Aviation Administration, 2016 ). The aspect of weight thus needs to be factored into the discussion. Considering the words remote-controlled, flight and weight leads one to conclude that drones were first used towards the end of the $20^{\text {th }}$ century, when newer technologies allowed for the inclusion of these factors into their design and development.

Moreover, the decline in cost due to these technological advancements has allowed drones to become viable options for a diverse range of services, including health services (Wulfovich, Rivas, \& Matabuena, 2018), agriculture (Parihar, Bhawsar, \& Hargod, 2016), sports (Park, Kim, \& Suh, 2018), conservation (Sandbrook, 2015) and in monitoring solar farms (Benatto et al., 2019). Drones have also been used in border patrol, disaster relief, law enforcement, and in the original use of military missions and training (Upchurch, 2015).

A specific research paper, published in 2019, described a novel way to reliably deliver packages using a drone. For years, companies such as Amazon and Google have been hard at work developing a safe and practical way of utilizing the potential of unmanned aerial vehicles to improve upon their current network of delivery services. Transportation 
of even large packages has become feasible due to the advances in drone-based robotics. The biggest problem left unanswered is how to best release the package once the drone has arrived at the drop off location. A possible solution details a basket that can hold onto the package until the drone is rapidly flipped upside down in an aerial maneuver (oftentimes called a roll) and the centrifugal force ejects the payload from the basket (Burke et al., 2019). However, this may prove draining to the battery.

Another option that overcomes this challenge involves a mechanism attached to the bottom of a drone that can deploy a payload from air to land using a parachute method. The study that reported on this release mechanism made use of an Arduino UNO microcontroller (Wan, Azrie, \& Shuib, 2018). This type of Arduino microcontroller can also be used in a practical test system to determine the reliability and consistency of operation of various release mechanisms relating to fishing-bait.

\section{INNOVATIVE TEST JIG DESIGN}

The practical test system of the innovative test jig is given in this section. Firstly, an overview of the complete test system is given, where after the load cell, instrumentation amplifier and the 24-bit analogue-to-digital converter is explained. The next step explains the Arduino software as well as the communication between the microcontroller, the SD card and the Nextion touch screen display. The complete block diagram of the tension release measurement system is shown in Figure 1.

The first block is a load cell that is rated for $5 \mathrm{~kg}$. The load cell has a safe overload of $6 \mathrm{~kg}$ and will be damaged if the load exceeds $7.5 \mathrm{~kg}$. The load cell has a measurement precision of $0.05 \%$. It is mounted with two x $5 \mathrm{~mm}$ bolts onto a fixed structure, while two x $4 \mathrm{~mm}$ bolts are used to connect to the load. One of the reasons why this load cell was selected is because of its ease of mounting. The load cell is constructed of four strain gauges that is coupled in a Wheatstone Bridge configuration. As the innovative test jig is custom made for release mechanisms for fish-bait, a $5 \mathrm{~kg}$ load cell is adequate. In order to perform accurate weight measurements, an instrumentation amplifier and higher resolution analogue to digital converter is necessary. 
The second and third blocks shows the instrumentation amplifier and the high precision 24-bit analogue to digital converter that is part of the HX711 load cell sensor interface module. The HX711 module was chosen for this project and is specially designed to work with strain gauges that is coupled in a Wheatstone Bridge configuration. It was used in load cell project involving a garbage alert system that was developed by the National Institute of Technology in India (Paavan, Sai, \& Naga, 2019). The HX711 module can be programmed for a gain of 32, 64 or 128 and it has an input voltage range of 4.8 to $5.5 \mathrm{~V}$ DC. The refresh frequency is selectable between 10 and $80 \mathrm{~Hz}$ and it has a low operating current of $1.6 \mathrm{~mA}$.

The center block in the diagram is the Arduino Mega microcontroller. It is used to obtain the high-resolution 24-bit data from the HX711 module and to do necessary processing. This process will be explained in the following section with the use of flow charts.

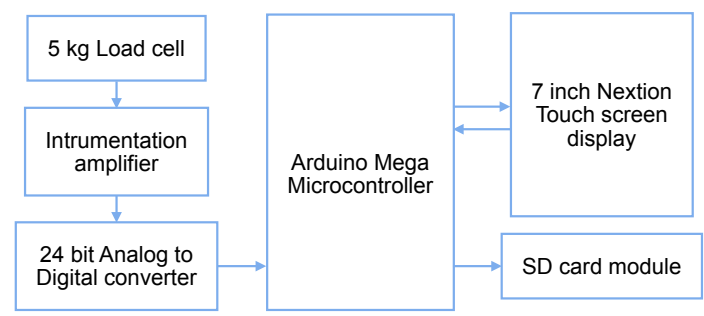

Figure 1. System block diagram.

The Arduino Mega microcontroller also saves the recorded data to a micro SD card that is situated on an SD module that fits as a shield on the Arduino. The microcontroller also connects to a 7-inch Nextion touchscreen display. This display is used as a user interface that shows recorded data while providing a number of push-button functions.

The Arduino program is presented in the form of a simplified flowchart as can be seen in Figure 2. Because of limitations in space, the flowchart only shows the major functions in the Arduino program to give the reader an idea of the general flow of data. After startup, the first block is the initialization bock where the necessary libraries for the display, the SD card and the HX711 module is loaded. After initialization, the weight measurements start and is displayed on the Nextion display. There are three push-button functions that can be selected by the user. 


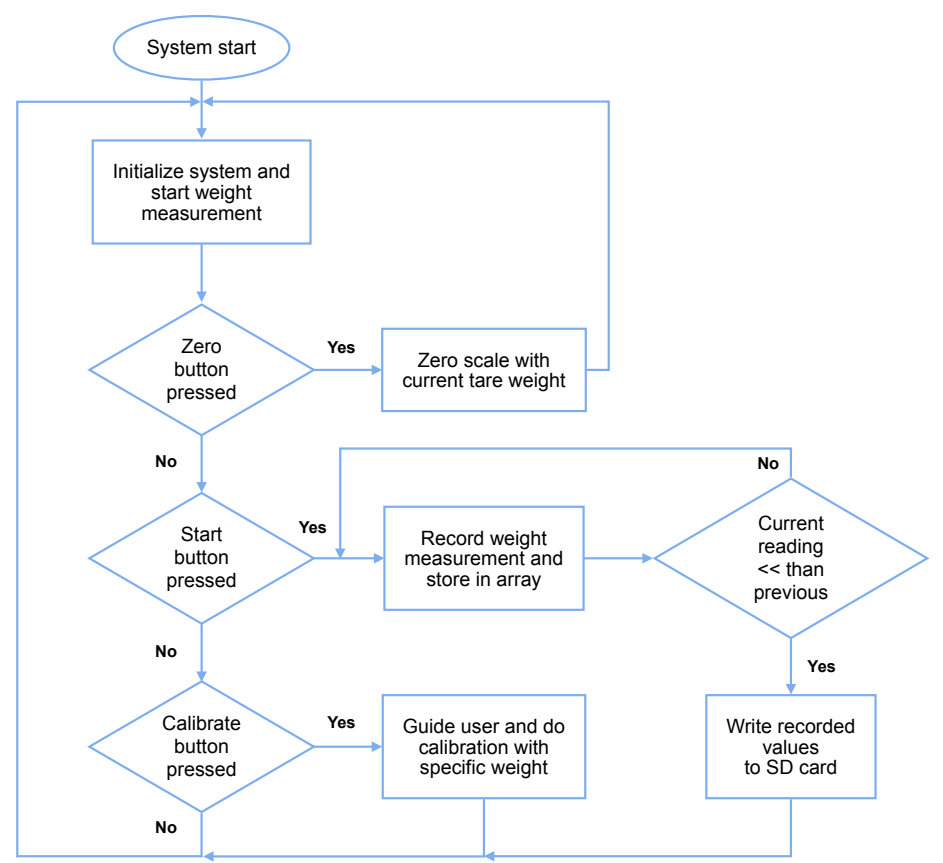

Figure 2. Simplified flow diagram of Arduino Mega program.

The first button is the calibration button that is used to calibrate the scale with a specific weight that is recorded in the program. If this button is pressed, the user must remove the load bucket and dropping mechanism from the load cell and connect a calibrated weight (333.2g) to the scale. The program will then do an automatic calibration to find the best calibration factor. There will also be a message on the screen that will notify the user when the calibration process is completed. Calibration is discussed in more detail later in the paper.

The zero button is used to zero the scale, with or without the tar weight, before the load bucket is connected to the dropping mechanism. The zero button also sets the experiment counter to zero that is used to identify the start of the recorded data that is sent to the SD card.

The next button is the start button and is used to start a test session where all weight measurements are recorded in an array. The weight is increased by allowing more water to flow into the load bucket by means of a water-value. After each measurement, a test is done to determine if the current measurement is smaller than the previous measurement. If not, 
then another measurement is done. As soon as the current measurement is smaller than the previous measurement then the system will detect that the release mechanism has activated. It will then display the maximum weight reading on the screen and write all the weight measurements in the array to the SD card. The number and name of the experiment is also recorded that specifies certain parameters about the fishing line that is used with the fishing-bait. The time taken, in milliseconds, to complete a series of measurements for each experiment is also recorded, along with the number of measurement samples and the number of milliliters (ml) per sample. As $1 \mathrm{ml}$ of water is equal $1 \mathrm{~g}$, the number of grams per sample can be used to calculate the accuracy of the measurement. For instance, if the weight increases with $1 \mathrm{~g}$ per sample then the maximum accuracy of the measurement cannot exceed $1 \mathrm{~g}$. After all the data is written to the SD card, a message is displayed on the Nextion display to inform the end user that the test system is ready for the next experiment session.

Calibration is done by using a specific calibrated weight. In this test system, a stainless-steel bar of $333.2 \mathrm{~g}$ is used. The exact weight of the bar was determined by using a calibrated scale (ADAM 6031) with a resolution of 0.1 gram. Figure 3 shows the flow diagram of the calibration sequence used in the Arduino program. When the zero button on the Nextion display is pushed, the scale is set to zero with the current tar. The user is then required to put the calibrated weight onto the scale, and the program executes a measurement command. If the measured weight is too high, then the calibration factor is decreased, and the measurement is repeated. If the measured weight is too low, then the calibration factor is increased, and the measurement is repeated. As soon as the measured weight is equal to the $333.2 \mathrm{~g}$ of the calibrated weight, then a completion message is communicated to the user via the Nextion display.

The Nextion touch screen display is used as a user interface for the test system. A photo of the display is shown in Figure 4. On the display, two measurements can be seen. The first measurement is the current reading from the load cell and the second reading is the last maximum reading recorded by the test system. On the bottom, left-hand corner are messages that have been communicated to the user. The three push-button functions can be seen on the bottom right side of the figure. 


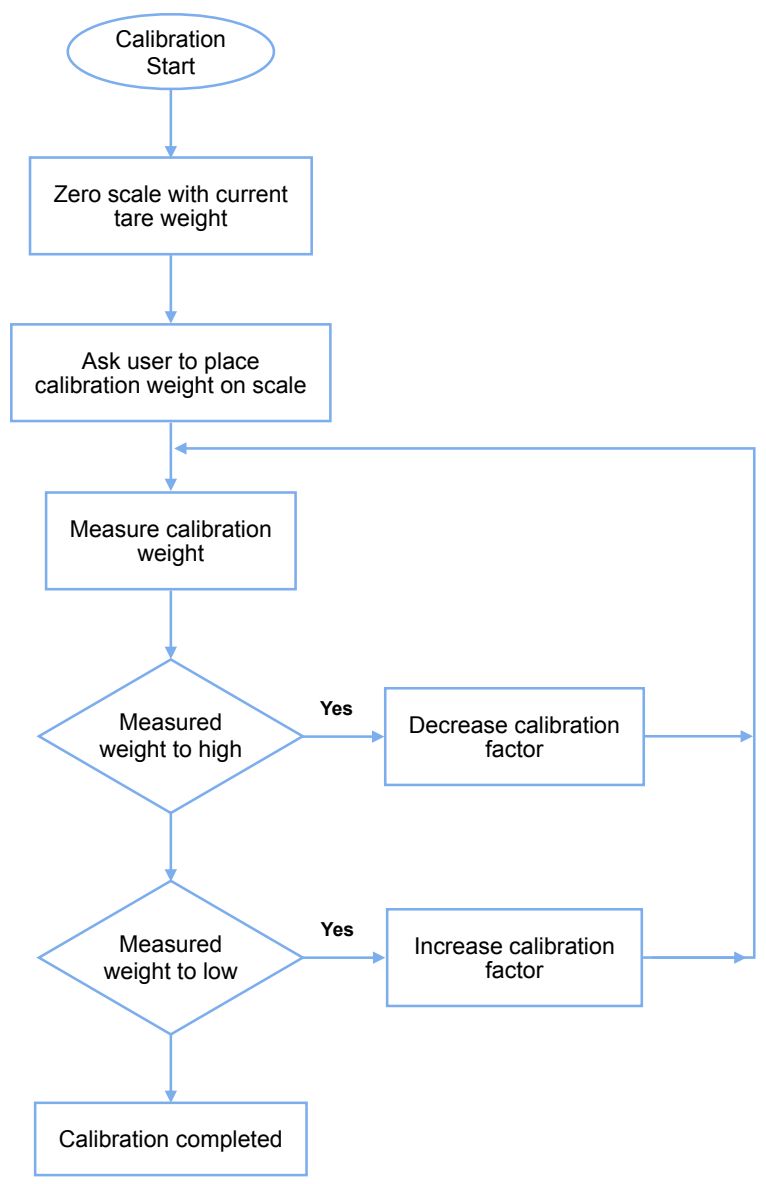

Figure 3. Simplified flow diagram of calibration software.

The calibration button (CAL) is used to calibrate the test system. The zero button (ZERO) is used to zero the scale with the tar weight. The start button (START) is used to start the experiment session. When the start button is pressed, the experiment number will be incremented by a value of 1 (the current value of 3 is shown in the top right-hand corner). The top left-hand corner shows the description of the experiment that can be changed in the Arduino software for each make of and model of the release mechanism. For instance, in Figure 4 it shows that the Gannet Sport release mechanism was used with a dry fishing line having a $0.55 \mathrm{~mm}$ diameter. It also shows that the test was concluded at $525 \mathrm{~g}$. 


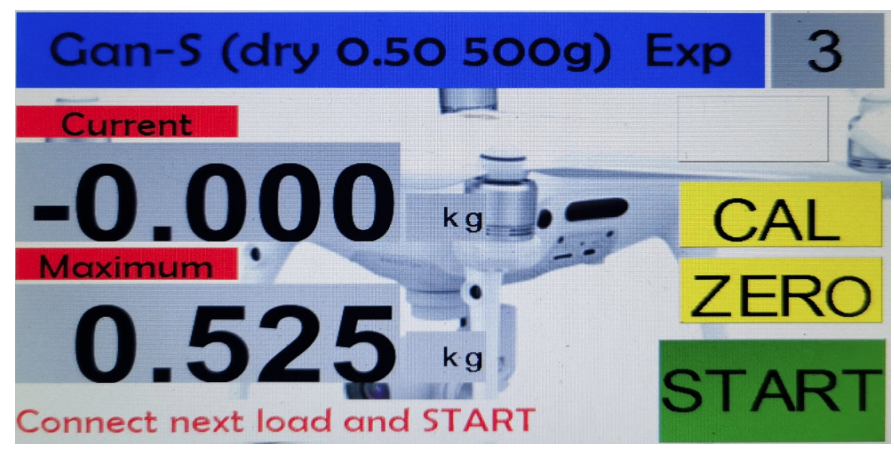

Figure 4. Nextion touch screen display showing the user interface.

Figure 5 shows a typical circuit and internal block diagram of the HX711 microchip. The HX711 load cell model has two analogue input channels (INA and INB). The differential inputs on the channel are coupled directly with the load cell Bridge sensor output. Channel INA can be programmed with a gain of 128 or 64 . These large gains are needed to accommodate the very small output signals from the strain gauge sensors. An input voltage of $+-20 \mathrm{mV}$ will result in a full-scale output of 5 volt with the 128 gain setting. Channel INB has a fixed gain of 32 and the input $\mathrm{V}$ range is $+-80 \mathrm{mV}$ for a full-scale output reading.

Figure 6 shows a photo of the completed practical test system. A two-liter water reservoir is located at the top of the system, which is used to increase the weight of the load bucket. The Nextion touch screen display, mounting bracket and dropping mechanism are also visible. Calibration weights are shown at the bottom of the photo.

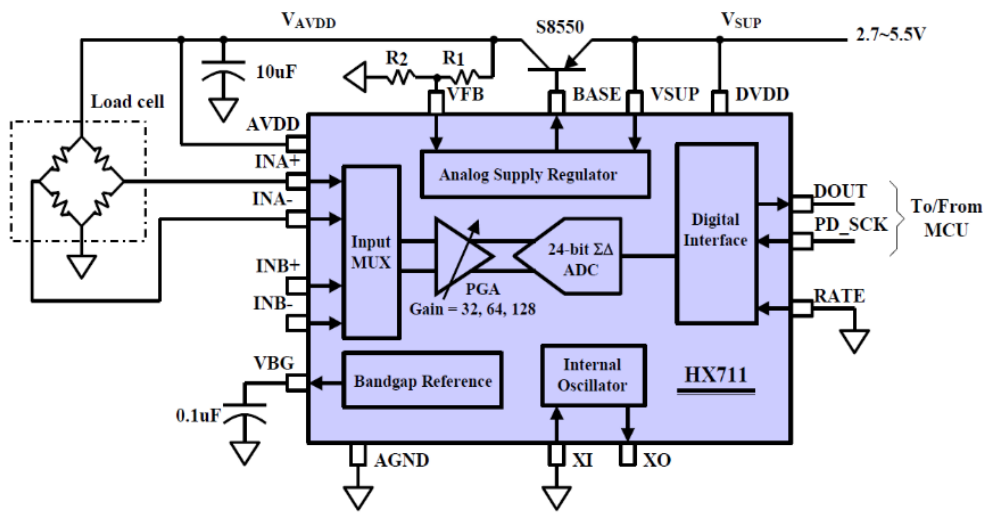

Figure 5. Typical circuit and internal block diagram of the HX711 microchip. Source: (Qian, Liu, \& Wu, 2019). 


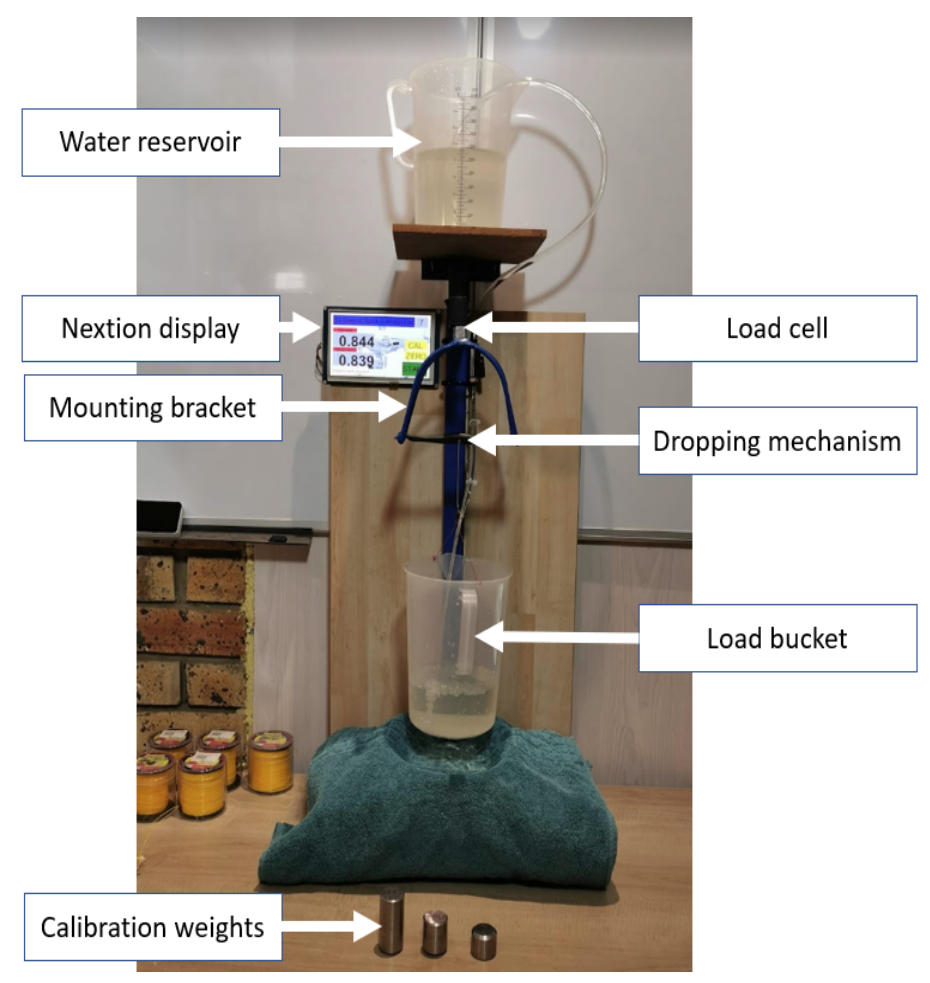

Figure 6. Practical setup of the innovative test jig for fishing-bait release mechanisms.

\section{METHOD}

In this section, the methodology will be explained. At startup, the system is first calibrated and then set to zero, and it will be reflected on the display. The next step will be to securely attach the release mechanism. Then the bucket is connected that will represent the load. The user then presses the start button on the touch screen display and opens the valve so that the water flows into the load bucket. Data from the load cell is recorded each second until the loading bucket is disconnected by the release mechanism. New readings are compared with previous readings to determine when the measurement process must stop. This occurs when the new readings are more than $10 \%$ lower than the previous readings. All sampled data is recorded to an SD card. The user will then empty the bucket and restart the experiment. This is repeated 10 times for each release mechanism to enhance the validity of the results and reliability of the innovative test jig. Validity usually refers to the degree that a measurement is a true reflection of the measurand (quantity intended to be measured), while reliability (also called precision) usually refers to the repeatability of the 
measurements. It must be noted that reliability is not always connected to the accuracy, but accuracy is linked to validity. An instrument may be reliable (measures the same value every time for a given parameter) but not accurate (measured value is repeatedly far off the true value).

\section{RESULTS}

In order to determine the accuracy of the designed system, the following was done. After the system had performed a self-calibration, three test weights were used to measure the accuracy of the system. The weight of these were measured using an accurate and calibrated scale (ADAM 6031). The resolution of the system was initially set to $0.1 \mathrm{~g}$ in the software. Ten consecutive measurements were done with the first test weight (144.6 grams). Recorded measurements ranged between 144.3 to 144.8 grams with a maximum deviation of $0.3 \mathrm{~g}$ from the true value. This was repeated for the other two weights. Recorded measurements for the $201.7 \mathrm{~g}$ weight ranged from 201.3 to $201.9 \mathrm{~g}$ with a maximum deviation of 0.4 g. Recorded measurements for the $333.3 \mathrm{~g}$ weight ranged from 332.8 to $333.4 \mathrm{~g}$ with a maximum deviation of $0.4 \mathrm{~g}$. The error percentage of the system was calculated to be $\pm 0,1 \%$ using the $333,5 \mathrm{~g}$ weight and its maximum deviation (translates to an accuracy of $99,879 \%$ ). Given this value, it was not deemed necessary for the system to display fractions of a gram and thus the resolution was set to $1 \mathrm{~g}$. This resolution is more than adequate for this type of experiment as the drone is expected to carry loads around $500 \mathrm{~g}$.

In order to test and demonstrate the practical usability of the innovative test jig, the following results are presented. Figure 7 shows the measurements for one experiment where a Gannet Sport release mechanism was used with a $0.55 \mathrm{~mm}$ line. It is evident from Figure 7 that the loading bucket weight was $193 \mathrm{~g}$ at the start of the experiment. As the water poured into the bucket at a constant rate, the weight increased to $835 \mathrm{~g}$ where the Gannet Sport released the load, and the measured weight drops down to zero. This point is recorded as the weight at which the release mechanism activates. 


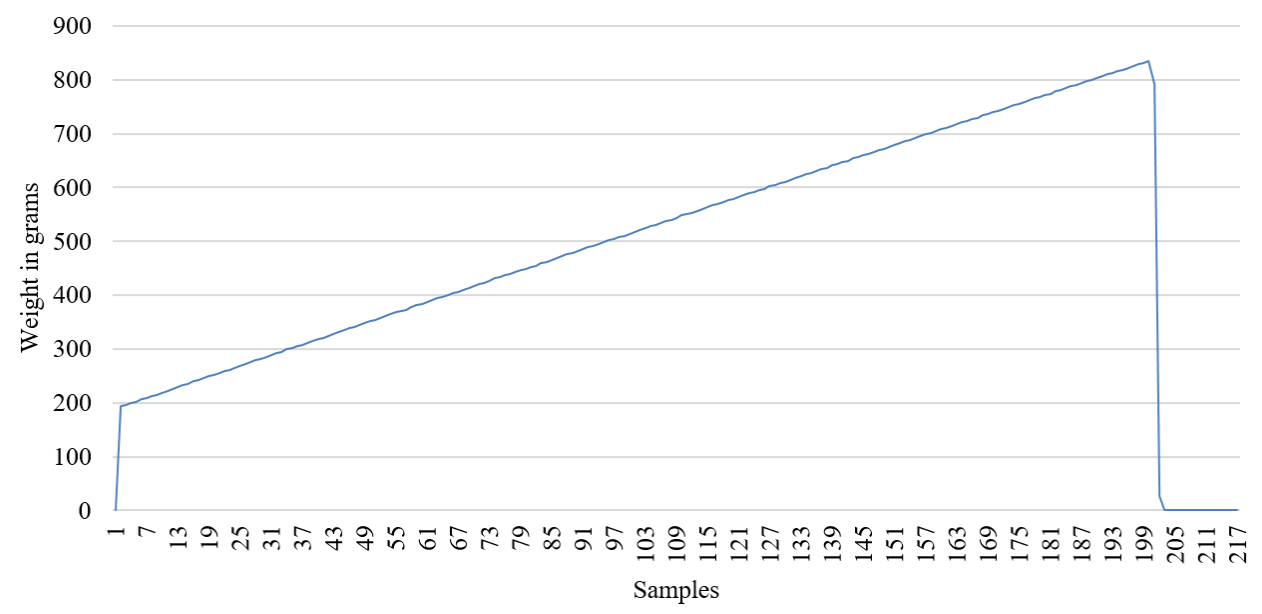

Figure 7. Data for one release experiment for the Gannet Sport with $0.55 \mathrm{~mm}$ line.

Figure 8 shows the maximum readings for ten consecutive readings where the Gannet sport was used with a $0.55 \mathrm{~mm}$ Kingfisher line. The maximum readings over the ten experiments ranged from 599 (reading no 1) to $642 \mathrm{~g}$ (reading no 5). Please note that no technical data is provided regarding the weights at which the release mechanism operates. This innovative jig and measurement system may now be used to clarify this.

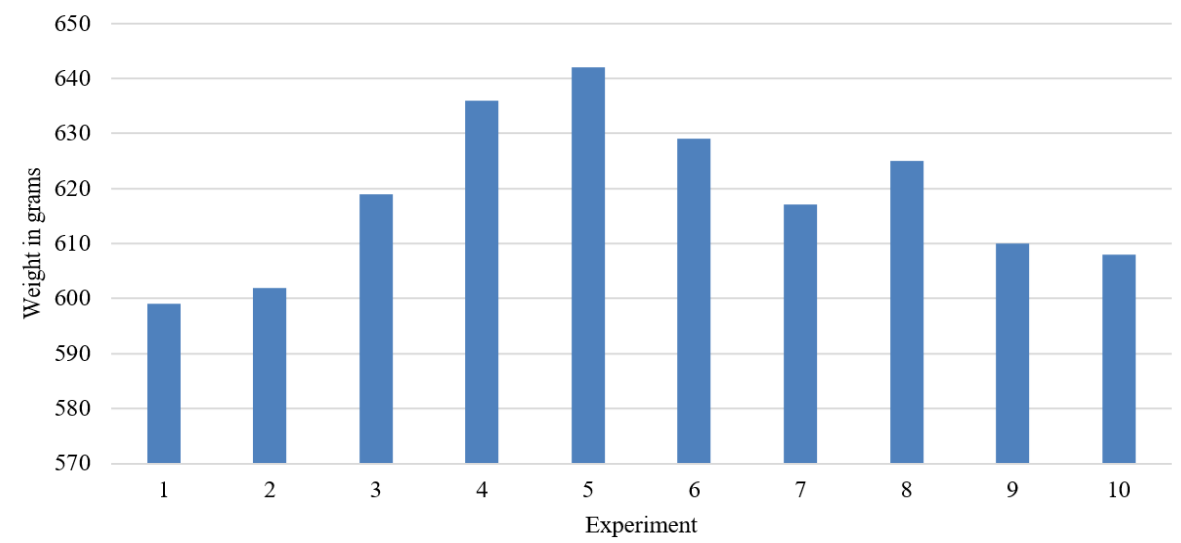

Figure 8. Recorded weights for the Gannet Sport with $0.55 \mathrm{~mm}$ line.

\section{CONCLUSIONS}

The purpose of this paper was to present a cost-effective and innovative test jig that may be used to determine the reliability and consistency of operation of various fishing-bait release mechanisms. The costs associated with the jig amount to $\$ 150$ where the main 
components are a HX711 instrumentation amplifier, a load cell and an Arduino Mega microcontroller. The accuracy of the system was determined to be $99,879 \%$. Reliability values for a Gannet Sport mechanism with a $0.55 \mathrm{~mm}$ Kingfisher line ranged from $599 \mathrm{~g}$ to $642 \mathrm{~g}$, giving a maximum deviation of $43 \mathrm{~g}$. The results provide evidence that the system can record measured values on an SD card for later use by the researcher. It may now be used to clarify technical data regarding the weights at which different fishing-bait release mechanisms operate.

\section{REFERENCES}

Benatto, G. A. D. R., Mantel, G., Riedel, N., Lancia, A. A. S., Thorsteinsson, S., Poulsen, P. B., Forchhammer, S., Parikh, H. R., Spataru, S. V., \& Séra, D. (2019). Drone-Based Daylight Electroluminescence Imaging of PV Modules. In Proceedings of 46th IEEE Photovoltaic Specialist Conference IEEE Press. https:/ / vbn.aau.dk/ en/publications/drone-based-daylight-electroluminescence-imaging-of-pv-modules

Brainy Quote. (2019, 2 January). http://www.brainyquote.com/quotes/

Burke, G., Nguyen, H., Magilligan, M., \& Noorani, R. (2019). Study of A Drone's Payload Delivery Capabilities Utilizing Rotational Movement. In International Conference on Robotics, Electrical and Signal Processing Techniques (ICREST), Dhaka, Bangladesh, 672675. https://doi.org/10.1109/ICREST.2019.8644318

Federal Aviation Administration. (2016, 28 June). Operation and certification of small unmanned aircraft systems. In 81 Federal Register 42063. https://www.federalregister. gov/documents/2016/06/28/2016-15079/operation-and-certification-of-smallunmanned-aircraft-systems

Ferrao, R. (2016). Drones and the Future of Armed Conflict. In 17 ISIL Year Book of International Humanitarian and Refugee Law (vol. 16), p. 270. 
Maksimovic, M. (2018). Greening the Future: Green Internet of Things (G-IoT) as a Key Technological Enabler of Sustainable Development. In Dey, N., Hassanien, A., Bhatt, C., Ashour, A., Satapathy, S. (eds) Internet of Things and Big Data Analytics Toward Next-Generation Intelligence. Studies in Big Data, (vol. 30). Springer, Cham. https://doi. org/10.1007/978-3-319-60435-0_12

Oxford Dictionary. (n.d.). http://www.oxforddictionaries.com/

Paavan, L. G. S., Sai, T. G., \& Naga, M. K. (2019). An IoT based Smart Garbage Alert System. In 3rd International Conference on Trends in Electronics and Informatics (ICOEI), Tirunelveli, India, 425-430. https://doi.org/10.1109/ICOEI.2019.8862518

Parihar, P., Bhawsar, P., \& Hargod, P. (2016). Design \& development analysis of quadcopter. COMPUSOFT, An international journal of advanced computer technology, 5(6), 2128. https://www.academia.edu/26483673/Design_and_Development_Analysis_ of_Quadcopter

Park, J., Kim, S., \& Suh, K. (2018). A comparative analysis of the environmental benefits of drone-based delivery services in urban and rural areas. Sustainability, 10(3), 888. https://doi.org/10.3390/su10030888

Qian, H., Liu, J., \& Wu, Y. (2019). A Self-Service Scheme of Infant Scale for Height and Weight. In IEEE MTT-S International Microwave Biomedical Conference (IMBioC), Nanjing, China, 1-3. https://doi.org/10.1109/IMBIOC.2019.8777754

Sandbrook, C. (2015). The social implications of using drones for biodiversity conservation. Ambio, 44(Suppl 4), 636-647. https://doi.org/10.1007/s13280-015-0714-0

SUAS News. (2019, 27 November). Gannet Pro fishing drone. https://www.suasnews. com/2019/10/gannet-pro-fishing-drone/

Upchurch, E. K. (2015). Drone on the Farm: The Benefits and Controversies Surrounding the Future of Unmanned Aircraft Systems in Agriculture. Drake Fournal of Agricultural Lawe, 20, 309. https://aglawjournal.wp.drake.edu/wp-content/uploads/ sites/66/2016/09/agVol20No2-upchurch.pdf 
Wan, W. M., Azrie, M. S., \& Shuib, A. (2018). Mechanism For Drones Delivering The Medical First Aid Kits. Advances in Transportation and Logistics Research, 1, 303-315. http://proceedings.itltrisakti.ac.id/index.php/ATLR/article/view/33

Wulfovich, S., Rivas, H., \& Matabuena, P. (2018). Drones in Healthcare. In Rivas H., Wac K. (eds) Digital Health. Health Informatics. Springer, Cham, 159-168. https://doi. org/10.1007/978-3-319-61446-5_11 
